\title{
Does inherited thrombophilia contributes thrombosis in microvascular free flap surgery: a pilot study.
}

\author{
Drizlionoka Gorovenko K, ${ }^{1,2}$ Stepanovs J., ${ }^{1,2}$ Ozolina A., ${ }^{1}$ Nikitina-Zake L., ${ }^{3}$ Mamaja B. ${ }^{1,2}$ \\ ${ }^{1}$ Riga Stradins University, Latvia \\ ${ }^{2}$ Riga East Clinical University Hospital, Latvia \\ ${ }^{3}$ Latvian Biomedical Research and Study Center, Latvia
}

\section{Background and Goal of study:}

The role of microvascular surgery as a part of reconstructive surgery is enhancing and has been technically improved, nevertheless mishap due to thrombosis still occures delaying restitution, thus bearing detrimental effect for patient, medical team and expenses.

Hereditery thrombophilia is a well known factor possessing increased risk for vascular events, however still beyond the scope of microvascular surgery. The goal of the study is to educe whether link between genetic factors and likelihood of thrombosis in microvascular free flap surgery exists.

\section{Material and Methods:}

60 patients undergone free flap microvascular surgery were enrolled in the cohort study.

Table 1. Phenotypic characteristics of the study group

\begin{tabular}{lll}
\hline & $\mathrm{n}=60$ & $(\%)$ \\
\hline Age, years (M; $\pm \mathrm{SD})$ & 39.35 & \\
& \pm 12.74 & \\
Sex, males & 53 & 88 \\
Risk factors, $\mathrm{n}$ & & \\
Recent trauma & 19 & 32 \\
Metabolic disturbances (DM, obesity) & 6 & 10 \\
Cardiovascular disease* & 3 & 5 \\
Other factors** & 6 & 10 \\
Smoking & 28 & 47 \\
\hline
\end{tabular}

*Cardiovascular pathology- MI, PAH, DVT

** Other factors- paraparesis, tetraparesis, spina bifida, epilepsy, neurofibroma

We selected nine single nucleotide polymorphisms (SNPs) reported to be associated with vascular thrombosis (Table 2).

\section{Results and Discussion:}

In 10/60 (17\%) patients free flap failure due to thrombosis occured.

We found SNP rs2289252 in $F 11$ and $r$ s13146272 in CYP4V2 in 7 and 5 patients in thrombosis group, respectively. Occurrence in non- thrombotic group of same SNPs is common either, both indicating high prevalence in observed population. (Table 3.)

rs6025 FV Leiden and rs1799963 Fll were found in nonthrombotic group but none in thrombotic group.

rs2227589 in SERPINC1 were identified in 4 patients with flap thrombosis and in 10 patients with non-thrombosis, including those (6) having perioperative thromboprophylaxis due to co-morbidities.

rs1613662 in GP6 along with history of myocardial infarction prior age of 45 were identified in 3 patients in non- thrombosis group with thromboprophylaxis.

Several SPNs combinations in thrombotic patients group were detected however no correlation was defined yet.

Table 3. Analysed SNPS

\begin{tabular}{|c|c|c|c|c|c|}
\hline Iable 3. Analysed SINPS & & & & & \\
\hline SNP (Gene) & Genotype & Thrombosis & Non- thrombosis & OR $(95 \% \mathrm{CI})$ & $\mathrm{p}$ value \\
\hline 1. rs5361 (SELE) & GG/GT/TT & $0 / 3 / 7$ & $1 / 7 / 42$ & $2.25(0.47-10.59)$ & 0.305 \\
\hline 2. $\mathrm{rs} 2227589$ (SERPINC1) & $\mathrm{TT} / \mathrm{CT} / \mathrm{CC}$ & $0 / 4 / 6$ & $0 / 10 / 40$ & $2.66(0.63-11.28)$ & 0.182 \\
\hline 3. $\operatorname{rs} 2066865(F G G)$ & AA/AG/GG & $0 / 3 / 7$ & $1 / 10 / 39$ & $1.51(0.33-6.87)$ & 0.587 \\
\hline 4. $r s 13146272(C Y P 4 V 2)$ & CC/AC/AA & $1 / 4 / 5$ & $2 / 26 / 22$ & $0.78(0.20-3.06)$ & 0.728 \\
\hline 5. $\quad \operatorname{rs} 2289252(F 11)$ & $\mathrm{TT} / \mathrm{CT} / \mathrm{CC}$ & $1 / 6 / 3$ & $4 / 21 / 25$ & $2.33(0.54-10.06)$ & 0.256 \\
\hline 6. $\operatorname{rs} 1613662(G P 6)$ & GG/AG/AA & $0 / 3 / 7$ & $1 / 8 / 41$ & $1.95(0.42-9.04)$ & 0.392 \\
\hline 7. $\operatorname{rs} 1801133$ (MTHFR) & AA/AG/GG & $0 / 4 / 6$ & $1 / 16 / 33$ & $1.29(0.32-5.21)$ & 0.717 \\
\hline 8. rs6025 (FV Leiden) & $\mathrm{TT} / \mathrm{CT} / \mathrm{CC}$ & $0 / 0 / 0$ & $0 / 2 / 58$ & - & - \\
\hline 9. rs1799963 (FII) & AA/AG/GG & $0 / 0 / 0$ & $0 / 1 / 59$ & - & - \\
\hline
\end{tabular}

Conclusion: Several gene polymorphisms are found in patients with thrombotic complications indicating a potential cause of microvascular free flap thrombosis likely synergistic with other well known thrombophilia contributing factors. Further data are mandatory and greater sample size is needed to set relationship between gene mutation and thrombosis in free flap surgery.
Table 2. Summary of selected SNPs

\begin{tabular}{ll}
\hline SNP (Gene) & Encoded proteins and their defects \\
\hline 1. rs5361 (SELE) & $\begin{array}{l}\text { Alteration of leukocyte- endothelial } \\
\text { interaction due to E- selectine enhanced } \\
\text { adhesion to leukocytes }\end{array}$ \\
2. rs2227589 (SERPINC1) & $\begin{array}{l}\text { Antithrombin (AT) deficiency- decreased } \\
\text { antigen level and functional activity (type I) } \\
\text { Increased level of fibrinogen }\end{array}$ \\
3. rs2066865 (FGG) & $\begin{array}{l}\text { Metabolic disorder of fatty acids } \\
\text { 4. rs13146272 (CYP4V2) }\end{array}$ \\
5. s2289252 (F11) & $\begin{array}{l}\text { Increased level of coagulation factor F11 (XI) } \\
\text { 6. rs1613662 (GP6) }\end{array}$ \\
7. rs1801133 (MTHFR) & $\begin{array}{l}\text { Increased level of homocysteine (inhibits } \\
\text { activation of protein C) }\end{array}$ \\
8. rs6025 (FV Leiden) & $\begin{array}{l}\text { Activated protein C resistance (APC), inability } \\
\text { to form protein C-FVa complex due to } \\
\text { defective FV } \\
\text { Increased prothrombin level }\end{array}$ \\
9. rs1799963 (FII) &
\end{tabular}

Figure 1. SNPs found in thrombosis group

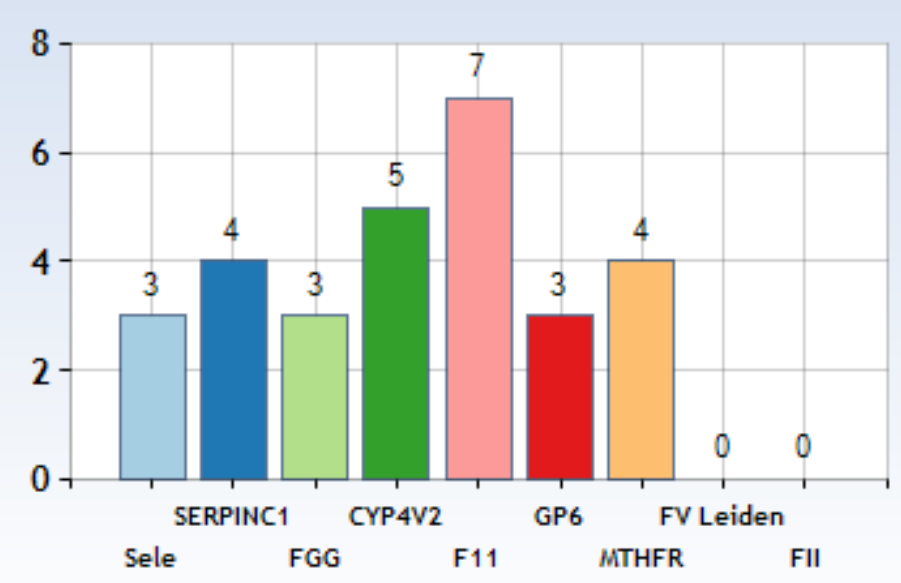

Figure 2. SNPs found in non-thrombosis group

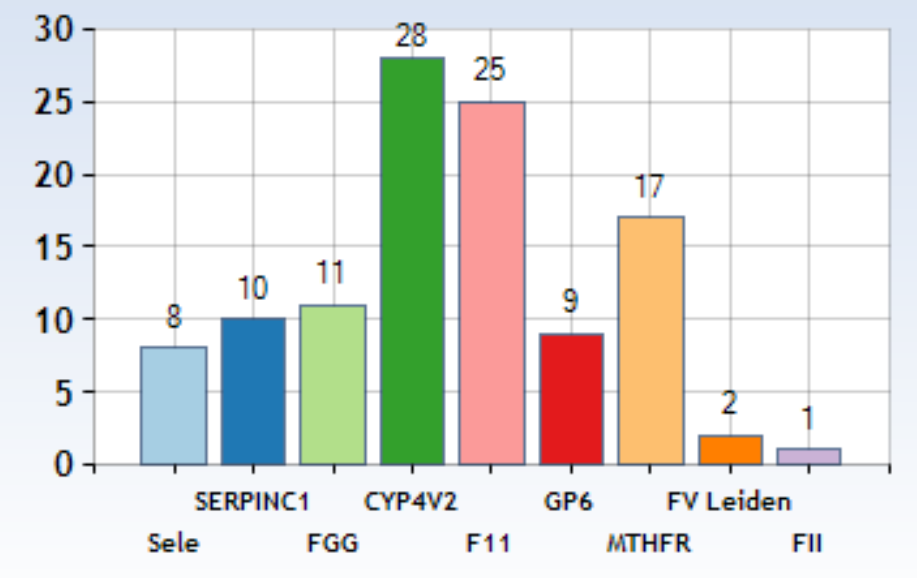

